\title{
VEREADORES E JUÍZES DE PAZ EM CURITIBA, ENTRE 1856 A 1889: A FORÇA POLÍTICA DAS FAMÍLIAS TRADICIONAIS ${ }^{1}$
}

\author{
Alessandro Cavassin Alves ${ }^{2}$
}

- Enviado em 16/04/2016

- Aprovado em 20/05/2016

\section{RESUMO}

Vereadores e juízes de paz no Império brasileiro formavam parte do poder político local, com a característica de serem escolhidos por eleições regulares, de maneira geral a cada quatro anos, pós 1828. Este trabalho possui como tema, portanto, apresentar quem foram estes políticos locais eleitos na cidade de Curitiba, capital do Paraná, entre 1856 a 1889, num total de 71 vereadores e 24 juízes de paz, levando em conta a genealogia destes políticos, família, esposa, idade, profissão e partido político. A metodologia utilizada para obter estas informações foi a leitura de jornais da época, documentos oficiais, como os relatórios dos Presidentes da Província do Paraná, as listas de votantes qualificados, as leis brasileiras referentes às Câmaras municipais e às eleições, além da "Genealogia paranaense", de Francisco Negrão e "O silêncio dos vencedores", de Ricardo Costa de Oliveira. Como resultado aponta-se para a fundamental importância das "famílias tradicionais" ou também chamadas de "famílias históricas do Paraná" no processo de acesso ao cargo de vereador ou juiz de paz.

Palavras-chave: Poder local. Genealogia. Família. Curitiba. Paraná. Brasil Século XIX

\section{INTRODUÇÃO}

A "vida política" do Império brasileiro, em relação ao poder local, dividia territorialmente suas províncias com cidades, vilas e freguesias, que elegiam seus vereadores e juízes de paz, tendo as paróquias e seus párocos como parte integrante desta organização. Pós 1824, as eleições passaram a ser necessárias e frequentes e bastante disputadas pelos "clãs eleitorais", organizados a partir de "clãs parentais", como diria Oliveira Viana ${ }^{3}$.

\footnotetext{
${ }^{1}$ Uma versão preliminar desse trabalho foi apresentada no GT1: INSTITUIÇÕES E PODER: PARENTESCOS E GENEALOGIAS do VII Seminário Nacional de Sociologia e Política da UFPR realizado de 11 a 13 de maio de 2016 em Curitiba.

2 Alessandro Cavassin Alves, Doutor em Sociologia pela UFPR, Professor na Faculdade São Basílio Magno (FASBAM) e Secretaria de Estado da Educação (SEED PR). E-mail: alessandrocavassin @ gmail.com

${ }^{3}$ Sobre "clãs eleitorais” e “clãs parentais”, conferir a reflexão de Oliveira VIANA (1987).
} 
Em relação ao processo eleitoral e o poder local, de acordo com a Lei das Câmaras Municipais de 01/10/1828, as eleições eram obrigatórias, com multa ao votante que não comparecesse sem justificativa. Os votantes eram anualmente cadastrados pelas juntas de qualificação, de acordo com sua renda, formando as listas de votantes qualificados. E quanto ao papel das Câmaras municipais, eram elas de caráter administrativo.

Neste sentido, sob este contexto histórico institucional, este trabalho visa entender quem foram os políticos eleitos para as vagas de vereadores e juízes de paz da cidade de Curitiba, capital da nova província do Paraná ${ }^{4}$, entre 1856 a 1889, tendo como referência a idade deles, suas atividades profissionais, o partido político e suas respectivas esposas. E como se verá ao longo do texto, tornar-se vereador em Curitiba exigia do indivíduo estar associado a uma tradicional família da região ${ }^{5}$, mesmo que por casamento, e a profissão deste político revela sua posição econômica nesta sociedade.

E, a partir da leitura dos periódicos locais de Curitiba e demais documentos do período, foi possível verificar a dinâmica eleitoral conduzida pelos "clãs parentais" e a importância dos dois partidos políticos deste momento, o Conservador e o Liberal, gerando os chamados, por Oliveira Viana, "clãs eleitorais".

\section{VEREADORES E JUÍZES DE PAZ DE CURITIBA (1856 a 1889)}

A Lei que regulou os processos eleitorais das décadas de 1850 a 1870 foi a de n. $^{\circ} 387$, de 19/08/1846. Era a eleição indireta, em que votantes deveriam escolher os vereadores e juízes de paz e, também, os eleitores, e estes deveriam posteriormente votar nos deputados e senadores.

A primeira eleição para a Câmara municipal de Curitiba, analisada neste trabalho, aconteceu no dia $07 / 09 / 1856^{6}$. Os votantes poderiam votar em nove candidatos, que era o número de vagas e mais quatro candidatos a juiz de paz, trazendo as duas cédulas preenchidas (para

\footnotetext{
${ }^{4}$ Com a emancipação política do Paraná em 1853, Curitiba foi escolhida como a capital da nova província. Era uma pequena cidade em 1853, com 6791 habitantes, sendo 678 escravos (PARANÁ, 1854).

${ }^{5}$ Por família tradicional considera-se aquela que há muito tempo reside em Curitiba e região, e com destaque econômico por possuírem fazendas, comércio, indústria de erva-mate, madeira, tropas de gado e mulas, e com profissões como funcionário público, advogado, médico, padre, engenheiro, militar e professor.

${ }^{6}$ Ocuparam o cargo de vereador no período de 1852 a 1856: Francisco de Paula Guimarães, Ignácio José Moraes, Francisco Borges de Macedo, Floriano Berlintes de Castro, Vicente Ferreira da Luz, Benedicto Enéas de Paula, Tobias Pinto Rebello, João Silveira de Miranda, Antonio Ricardo Lustosa de Andrade, Padre João de Abreu Sá Sotto Maior e Bento Florêncio Munhoz. Era juiz de paz Manoel de Oliveira Franco (Dezenove de Dezembro, 1855 e 1856).
} 
vereadores e para juízes de paz) e devidamente assinada, entregando-a para a mesa receptora, na Igreja Matriz da capital ${ }^{7}$.

Tabela 1 - Vereadores e Juízes de Paz de Curitiba, 1857-1860

\begin{tabular}{|c|c|c|c|c|c|}
\hline VEREADORES - Curitiba & Votos & Idade & Profissão & Partido & Esposa / Ano casamento \\
\hline $\begin{array}{l}\text { 1. Dr. Jesuíno Marcondes de } \\
\text { Oliveira e Sá (Presidente) }\end{array}$ & 1013 & 29 & $\begin{array}{l}\text { Advogado, } \\
\text { Tropeiro }\end{array}$ & $\begin{array}{l}\text { Liberal, } \\
\text { chefe }\end{array}$ & $\begin{array}{l}\text { Domitilia Alves de Araujo, } \\
\text { em } 1855\end{array}$ \\
\hline $\begin{array}{l}\text { 2. Padre João de Abreu Sá } \\
\text { Sotto Maior, Alferes capelão }\end{array}$ & 980 & 61 & $\begin{array}{l}\text { Padre, } \\
\text { Fazendeiro }\end{array}$ & Liberal & Solteiro \\
\hline $\begin{array}{l}\text { 3. Ignácio José Moraes, } \\
\text { Major, Tenente Coronel }\end{array}$ & 964 & 43 & $\begin{array}{l}\text { Funcionário } \\
\text { público, } \\
\text { Negociante }\end{array}$ & $\begin{array}{l}\text { Liberal, } \\
\text { chefe }\end{array}$ & $\begin{array}{l}\text { Anna Francisca Teixeira, em } \\
1868 ;\end{array}$ \\
\hline $\begin{array}{l}\text { 4. Benedicto Enéas de Paula, } \\
\text { Capitão }\end{array}$ & 959 & 31 & $\begin{array}{l}\text { Negociante, } \\
\text { Obras } \\
\text { públicas }\end{array}$ & $\begin{array}{l}\text { Liberal, } \\
\text { chefe }\end{array}$ & $\begin{array}{lrr}\text { Zeferina } & \text { Candida } & \text { do } \\
\text { Nascimento, em } 1848 & \end{array}$ \\
\hline $\begin{array}{l}\text { 5. Joaquim Lourenço de Sá } \\
\text { Ribas, Capitão }\end{array}$ & 954 & 33 & $\begin{array}{l}\text { Funcionário } \\
\text { público }\end{array}$ & Liberal & Solteiro \\
\hline $\begin{array}{l}\text { 6. Manoel [José] de Freitas } \\
\text { Saldanha, Tenente }\end{array}$ & 930 & 32 & $\begin{array}{l}\text { Funcionário } \\
\text { público, } \\
\text { Negociante }\end{array}$ & Liberal & $\begin{array}{l}\text { Ilecta da Silva [Electa Maria } \\
\text { Caetano], em } 1846\end{array}$ \\
\hline $\begin{array}{l}\text { 7. Floriano Berlintes de } \\
\text { Castro, Tenente Coronel }\end{array}$ & 882 & 49 & $\begin{array}{l}\text { Funcionário } \\
\text { público, } \\
\text { Negociante }\end{array}$ & Liberal & $\begin{array}{l}\text { Francisca de Paula Alves, } \\
\text { falecida em 1864; } 2^{\mathrm{a}} \text { núpcias } \\
\text { com Maria da Conceição } \\
\text { Saldanha }\end{array}$ \\
\hline $\begin{array}{l}\text { 8. Bento Florêncio Munhoz, } \\
\text { Major }\end{array}$ & 846 & 30 & $\begin{array}{l}\text { Industrial } \\
\text { erva-mate, } \\
\text { Negociante }\end{array}$ & Conservador & Maria do Céo Taborda Ribas \\
\hline $\begin{array}{l}\text { 9. Antonio Ricardo Lustosa } \\
\text { de Andrade, Tenente Coronel }\end{array}$ & 821 & 31 & $\begin{array}{l}\text { Funcionário } \\
\text { público }\end{array}$ & Conservador & Gabriella Franco \\
\hline Seguem os suplentes & - & & & & \\
\hline JUÍZES DE PAZ - Curitiba & Votos & Idade & Profissão & Partido & Esposa / Ano casamento \\
\hline $\begin{array}{l}\text { 1. João Baptista Brandão de } \\
\text { Proença, Capitão }\end{array}$ & 542 & 41 & Professor & Liberal & $\begin{array}{l}\text { Theolinda Affonso [Maria } \\
\text { Theolinda de Jesus] }\end{array}$ \\
\hline $\begin{array}{l}\text { 2. Manoel Gonçalves de } \\
\text { Moraes Roseira, Comendador }\end{array}$ & 533 & 56 & $\begin{array}{l}\text { Fazendeiro, } \\
\text { Negociante }\end{array}$ & Conservador & $\begin{array}{llll}\text { Maria Rosa } & \text { de } & \text { Moraes } \\
\text { Roseira } & & & \\
\end{array}$ \\
\hline $\begin{array}{l}\text { 3. Manoel Antonio Ferreira, } \\
\text { Tenente Coronel }\end{array}$ & 523 & 51 & $\begin{array}{l}\text { Fazendeiro, } \\
\text { Obras } \\
\text { públicas }\end{array}$ & $\begin{array}{l}\text { Liberal, } \\
\text { chefe }\end{array}$ & $\begin{array}{llll}\text { Florinda } & \text { Maurícia } & \text { de } & \text { Sá } \\
\text { Ribas, em } 1832 & & \end{array}$ \\
\hline $\begin{array}{lcc}4 . & \text { Francisco } & \text { Antonio } \\
\text { Nóbrega, Capitão } & \end{array}$ & 448 & 33 & Negociante & Liberal & $\begin{array}{l}\text { Rita Maria Miró, falecida em } \\
1856 ; \quad 2^{\mathrm{a}} \text { núpcias, com } \\
\text { Escolástica Silveira Miró de } \\
\text { Miranda, em } 1857\end{array}$ \\
\hline Seguem suplentes & - & & & & \\
\hline
\end{tabular}

Fonte: O Dezenove de Dezembro, 17/09/1856 (para o resultado eleitoral); Lista de Votantes qualificados de Curitiba, 1855 e 1861 (idade e profissão); NEGRÃO, 1926, 1927, 1928, 1929, 1946, 1950 (para as demais informações).

\footnotetext{
${ }^{7}$ A Lei geral de 01/10/1828, art. 23, restringia o voto para pessoas da mesma família: "Não podem servir de Vereadores conjuntamente no mesmo ano, e na mesma cidade, ou vila: pai, e filho, irmão, ou cunhados, enquanto durar o cunhadio, devendo, no caso de serem nomeados, preferir o que tiver maior número de votos".
} 
Desta tabela pode-se observar as tradicionais famílias residentes na região de Curitiba, como a família Sá Ribas ${ }^{8}$ e a família Lustosa de Andrade ${ }^{9}$. As demais famílias irão ser destacadas ao longo das outras legislaturas.

Enfim, esta foi uma Câmara com as principais lideranças do partido Liberal, agremiação política bastante forte no sul do Brasil, da qual pode-se dizer ser um grande "clã parental", liderado pelos tropeiros da família do Dr. Jesuino Marcondes de Oliveira e $S^{10}$, e pela família dos Sá Ribas em Curitiba; mas com a presença de três políticos Conservadores, liderados por Manoel de Oliveira Franco, em Curitiba, proveniente de uma dissidência dentro da própria família Sá Ribas; no campo das profissões, destacou-se a predominância de negociantes e funcionários públicos, demonstrando a importância deles ocuparem este cargo público. Quanto às mulheres, o exemplo de Gabriella Franco, irmã de Manoel de Oliveira Franco (presidente da mesa receptora de votos desta eleição e juiz de paz), casada com Antonio Ricardo Lustosa de Andrade, juntando as famílias do português João Gonçalves Franco (pai de Gabriella e Manoel) e que foi juiz ordinário em Curitiba, com a tradicional família Lustosa de Andrade; outro exemplo seria Florinda Maurícia de Sá Ribas, irmã do vereador Joaquim Lourenço de Sá Ribas, casada com Manoel Antonio Ferreira, juiz de paz; e Escolástica Joaquina de Sá Ribas, irmã de Florinda e Joaquim, casada com o próprio Manoel de Oliveira Franco, mas que por desavenças em 1841 acabaram representando o partido conservador em Curitiba (ALVES, 2015, p.54).

A próxima eleição municipal aconteceu quatro anos depois, no dia 07/09/1860, num período em que os Conservadores estavam no poder político no Rio de Janeiro. E Curitiba demonstra ser mesmo um reduto dos Liberais, deste "clã eleitoral" da família do Dr. Jesuino Marcondes e dos Sá Ribas. A renovação foi de cinco novos vereadores.

\footnotetext{
${ }^{8}$ Como exemplo, o patriarca desta família Sá Ribas, o Dr. Lourenço Ribeiro de Andrade talvez seja o primeiro filho de Curitiba a estudar em Portugal, universidade de Coimbra, recebendo o título de licenciado por volta de 1747, sendo capitão mor desta cidade entre 1765 a 1799 e depois seu filho Antonio Ribeiro de Andrade assume esse cargo entre 1800 a 1821 (LEÃO, Ermelino, 1926, p.1168-1169). Esta família descente do "grupo de João Rodrigues Seixas". João Rodrigues Seixas foi um dos primeiros povoadores de Curitiba e ao ser criada a justiça e o governo da Vila, foi o primeiro Escrivão da Câmara (OLIVEIRA, 2001, p.406)
}

${ }^{9}$ O Sargento Mor Ignácio Lustosa de Andrade casou em Paranaguá com Maria Catharina de Moraes Cordeiro. Ele faleceu em Curitiba a 20/09/1834 e ela em 1844. Ela de família natural de Paranaguá, ele de família natural de Curitiba descendente do Capitão Balthazar Carrasco dos Reis, que se mudou com toda sua família para Curitiba onde faleceu em 1697 com testamento. A genealogia desta família está disponível em: http://www.buratto.org/paulistana/Carrascos.htm. Acesso em 19/11/2015. Conferir, também, NEGRÃO (1927) e OLIVEIRA (2001, p.389).

${ }^{10}$ Jesuino Marcondes de Oliveira e Sá, sua mãe, Querubina Marcondes de Sá (baronesa de Tibagi), era descendente de Balthazar Carrasco dos Reis (NEGRÃO, 1926, p.374-397). 
Tabela 2 - Vereadores e Juízes de Paz de Curitiba, 1861-1864

\begin{tabular}{|c|c|c|c|c|c|}
\hline VEREADORES - Curitiba & Votos & Idade & Profissão & Partido & Esposa / Ano casamento \\
\hline $\begin{array}{l}\text { 1. Dr. Augusto Lobo de Moura } \\
\text { (Presidente) }\end{array}$ & 1088 & 50 & Advogado & Liberal & Julia de Andrade \\
\hline $\begin{array}{l}\text { 2. Joaquim Lourenço de Sá Ribas, } \\
\text { Capitão }\end{array}$ & 1083 & \multicolumn{4}{|c|}{ Reeleito - Liberal } \\
\hline $\begin{array}{l}\text { 3. Tibúrcio Borges de Macedo, } \\
\text { Capitão }\end{array}$ & 1078 & 32 & Negociante & Liberal & $\begin{array}{l}\text { Anna Rufina Ribas de } \\
\text { Macedo, } 1858 \text { em Castro }\end{array}$ \\
\hline 4. Benedicto Enéas de Paula, Major & 1077 & \multicolumn{4}{|c|}{ Reeleito - Liberal, chefe } \\
\hline 5. Candido Martins Lopes & 1077 & 58 & $\begin{array}{l}\text { Proprietário } \\
\text { do jornal } \\
\text { Dezenove de } \\
\text { Dezembro }\end{array}$ & Liberal & $\begin{array}{l}\text { Gertrudes da Silva Lopes, } \\
1836 \text { no Rio de Janeiro }\end{array}$ \\
\hline $\begin{array}{l}\text { 6. Manoel [José] de Freitas Saldanha, } \\
\text { Tenente }\end{array}$ & 1072 & \multicolumn{4}{|c|}{ Reeleito - Liberal } \\
\hline $\begin{array}{l}\text { 7. Floriano Berlintes de Castro, } \\
\text { Capitão }\end{array}$ & 1068 & \multicolumn{4}{|c|}{ Reeleito - Liberal } \\
\hline 8. Francisco Pereira Alves, Coronel & 1068 & 40 & $\begin{array}{l}\text { Negociante, } \\
\text { Funcionário } \\
\text { público }\end{array}$ & Liberal & $\begin{array}{l}\text { Escolástica Maria de } \\
\text { Lima, em } 1858\end{array}$ \\
\hline $\begin{array}{l}\text { 9. Manoel Gonçalves dos Santos, } \\
\text { Tenente }\end{array}$ & 1065 & 33 & Negociante & Liberal & $\begin{array}{l}\text { Maria Ritta dos Santos, } \\
\text { em } 1846\end{array}$ \\
\hline Seguem suplentes & - & & & & \\
\hline JUÍZES DE PAZ - Curitiba & Votos & Idade & Profissão & Partido & Esposa / Ano casamento \\
\hline $\begin{array}{l}\text { 1. João Baptista Brandão de Proença, } \\
\text { Capitão }\end{array}$ & 754 & \multicolumn{4}{|c|}{ Reeleito - Liberal } \\
\hline $\begin{array}{l}\text { 2. João Manoel da Cunha, Tenente } \\
\text { Coronel }\end{array}$ & 745 & 40 & $\begin{array}{l}\text { Advogado } \\
\text { provisionado, } \\
\text { Professor } \\
\end{array}$ & Liberal & Maria Elisa da Cunha \\
\hline 3. João José de Freitas Saldanha & 742 & 43 & Negociante & Liberal & $\begin{array}{l}\text { Anna Maria do } \\
\text { Sacramento, em } 1845 ; 2^{\text {a }} \\
\text { núpcias, com Zeferina } \\
\text { Maria Luiza, em } 1857\end{array}$ \\
\hline $\begin{array}{l}\text { 4. Dr. Jesuíno Marcondes de Oliveira } \\
\text { e Sá }\end{array}$ & 741 & \multicolumn{4}{|c|}{ Reeleito - Liberal } \\
\hline Seguem suplentes & - & & & & \\
\hline
\end{tabular}

Fonte: O Dezenove de Dezembro, 24/10/1860 (para o resultado eleitoral); Lista de Votantes qualificados de Curitiba, 1855 e 1861 (idade e profissão); NEGRÃO, 1926, 1927, 1928, 1929, 1946, 1950 (para as demais informações).

Esta foi uma Câmara de vereadores composta por políticos Liberais, mesmo sendo o Gabinete imperial dominado por Conservadores, no Rio de Janeiro. E, novamente, há a predominância de funcionários públicos e negociantes. Destaca-se o tipógrafo jornalista Candido Martins Lopes, proprietário do jornal Dezenove de Dezembro. Dentre as tradicionais famílias podem-se destacar os Borges de Macedo ${ }^{11}$.

\footnotetext{
${ }^{11}$ A família Borges de Macedo era descendente de Baltazar Carrasco dos Reis. A referência política foi o ajudante José Borges de Macedo, natural de Castro, que transfere-se para Curitiba sendo negociante, e torna-se prefeito em 1835, cargo criado mas logo extinto em 1838, além de ser eleito várias vezes como juiz de paz. Portanto, considerado o primeiro prefeito de Curitiba. Vários políticos ao longo do tempo no Paraná são desta família (OLIVEIRA, 2001).
} 
A próxima eleição municipal, depois de quatro anos, aconteceu no dia 07/09/1864. O Brasil, neste momento, era regido por um Gabinete Liberal, dos chamados políticos da Liga ou Progressistas, que tinham assumido o poder em maio de 1862.

Tabela 3 - Vereadores e Juízes de Paz de Curitiba, 1865-1868

\begin{tabular}{|c|c|c|c|c|c|}
\hline VEREADOR - Curitiba & Votos & Idade & Profissão & Partido & Esposa / Ano do casamento \\
\hline 1. Dr. Augusto Lobo de Moura & 1387 & \multicolumn{4}{|c|}{ Reeleito - Liberal } \\
\hline 2. Dr. José Lourenço de Sá Ribas & 1359 & 45 & $\begin{array}{l}\text { Advogado, } \\
\text { Funcionário } \\
\text { público }\end{array}$ & $\begin{array}{l}\text { Liberal, } \\
\text { chefe }\end{array}$ & Felicidade Mourão de Pinho \\
\hline $\begin{array}{l}\text { 3. Tiburcio Borges de Macedo, } \\
\text { Capitão }\end{array}$ & 1346 & \multicolumn{4}{|c|}{ Reeleito - Liberal } \\
\hline $\begin{array}{l}\text { 4. João Manoel da Cunha, Tenente } \\
\text { Coronel }\end{array}$ & 1319 & \multicolumn{4}{|c|}{ Reeleito - Liberal } \\
\hline $\begin{array}{l}\text { 5. Floriano Berlintes de Castro, } \\
\text { Capitão }\end{array}$ & 1143 & \multicolumn{4}{|c|}{ Reeleito - Liberal } \\
\hline 6. Candido Martins Lopes & 997 & \multicolumn{4}{|c|}{ Reeleito - Liberal } \\
\hline $\begin{array}{l}\text { 7. Fernando Martins França, Tenente } \\
\text { Coronel }\end{array}$ & 818 & 46 & $\begin{array}{l}\text { Negociante } \\
\text { de tropas }\end{array}$ & Liberal & $\begin{array}{l}\text { Emília Vidalina, no Rio } \\
\text { Grande do Sul }\end{array}$ \\
\hline 8. Sizenando de Sá Ribas, Capitão & 794 & 31 & Negociante & Liberal & $?$ \\
\hline 9. João José de Freitas Filho, Tenente & 753 & 35 & $\begin{array}{l}\text { Funcionário } \\
\text { Público, } \\
\text { Negociante }\end{array}$ & Liberal & $\begin{array}{l}\text { Porfiria Maria da Conceição } \\
\text { Freitas }\end{array}$ \\
\hline Suplentes & \multicolumn{5}{|l|}{-} \\
\hline JUIZES DE PAZ - Curitiba & Votos & Idade & Profissão & Partido & Esposa / Ano casamento \\
\hline 1. João Baptista Brandão de Proença & 836 & \multicolumn{4}{|c|}{ Reeleito - Liberal } \\
\hline 2. Tiburcio Borges de Macedo & 799 & \multicolumn{4}{|c|}{ Reeleito - Liberal } \\
\hline 3. Ildefonso Marques dos Santos & 691 & 31 & Negociante & Liberal & Solteiro \\
\hline $\begin{array}{llll}\text { 4. Antonio Augusto Ferreira de } \\
\text { Moura }\end{array}$ & 596 & 20 & Negociante & Liberal & $\begin{array}{l}\text { Porcina Margarida de } \\
\text { Oliveira Borges, falecida em } \\
\text { 1884; } 2^{\mathrm{a}} \text { núpcias com Brasília } \\
\text { Gonçalves; }\end{array}$ \\
\hline Seguem os suplentes & \multicolumn{5}{|c|}{ - } \\
\hline
\end{tabular}

Fonte: Dezenove de Dezembro, 14/09/1864 (para o resultado eleitoral); Lista de Votantes qualificados de Curitiba, 1855 e 1861 (idade e profissão); NEGRÃO, 1926, 1927, 1928, 1929, 1946, 1950 (para as demais informações).

Na Câmara de Curitiba os Liberais continuaram a predominar; as profissões dominantes continuam a ser a de funcionários públicos e negociantes; em relação às famílias, destaca-se a família Ferreira de Moura e Marques dos Santos ${ }^{12}$.

E a segunda metade da década de 1860 no Brasil passou a ser bastante intensa, principalmente devido ao acontecimento da Guerra do Paraguai (1864-1870). E a próxima eleição

12 O português Dr. Augusto Lobo de Moura chega em Curitiba em 1836, casa com Julia de Andrade, de tradicional família Lustosa de Andrade, e seus filhos também se casam com as tradicionais famílias paranaenses, como o capitão Antonio Augusto Ferreira de Moura, casado com Porcina Margarida de Oliveira Borges; já os Marques dos Santos são descendentes do português Miguel Marques dos Santos, falecido em 1848 e de Generosa Luciana de Chaves, falecida em Curitiba, em 22/07/1879. Generosa Luciana de Chaves é filha de Maria Bandeira de Jesus e do capitão Luciano José de Chaves (NEGRÃO, 1926, p.586). Isto os aproxima da mãe de outro importante político Benedicto Enéas de Paula, filho de Francisca Luciana Chaves, provável irmã de Generosa Luciana de Chaves. Elas são descendentes de Baltazar Carrasco dos Reis que faleceu em Curitiba em 1697, com testamento. 
municipal aconteceu dia 07/09/1868, em plena Guerra do Paraguai. Neste clima de intenso conflito externo, D. Pedro II fez uma mudança drástica de Gabinete no Rio de Janeiro, trazendo de volta ao poder os Conservadores, em 16/07/1868, com o Visconde de Itaboraí como presidente deste Ministério $^{13}$.

Apesar desta mudança de Gabinete no Rio de Janeiro, em Curitiba os Liberais venceram as eleições municipais de 07 de setembro, demonstrando que ainda não tinham sido desarticulados pelos Conservadores paranaenses, aparentemente desorganizados, sob a liderança em Curitiba de Manoel de Oliveira Franco.

E, como demonstra a leitura dos periódicos da época, as lutas partidárias entre Liberais e Conservadores passaram a ser muito mais acirradas e intensas a partir da volta dos Conservadores ao poder no Rio de Janeiro. Oliveira Viana, como dito, interpreta estas lutas partidárias como a dinâmica própria dos "clãs parentais" tendo que vencer as eleições, para terem a seu favor os benefícios e p controle do poder público. Para tanto, tinham que organizar seus "votantes" e combater os adversários de outros "clãs parentais". Era a operacionalização do chamado "clã eleitoral".

Tabela 4 - Vereadores e Juízes de Paz em Curitiba, 1869-1871

\begin{tabular}{|l|l|l|l|l|l|}
\hline VEREADOR - Curitiba & Votos & Idade & Profissão & Partido & Esposa / Ano casamento \\
\hline $\begin{array}{l}\text { 1. Dr. José Lourenço de Sá Ribas } \\
\text { (Presidente) }\end{array}$ & 810 & Reeleito - Liberal \\
\hline 2. Sizenando de Sá Ribas, Capitão & 790 & Reeleito - Liberal \\
\hline $\begin{array}{l}\text { 3. Ignácio José Moraes, Tenente } \\
\text { Coronel }\end{array}$ & 789 & Reeleito - Liberal \\
\hline $\begin{array}{l}\text { 4. Dr. Generoso Marques dos } \\
\text { Santos }\end{array}$ & 788 & 25 & Advogado & Liberal & $\begin{array}{l}\text { Ana Joaquina de Paula, } \\
\text { em 1871 }\end{array}$ \\
\hline $\begin{array}{l}\text { 5. Dr. Sergio Francisco de Souza } \\
\text { Castro }\end{array}$ & 788 & 29 & Advogado & Liberal & $\begin{array}{l}\text { Francisca Gonçalves dos } \\
\text { Santos, em 1863 }\end{array}$ \\
\hline $\begin{array}{l}\text { 6. Dr. Joaquim Ignácio Silveira da } \\
\text { Mota Junior }\end{array}$ & 787 & 25 & Advogado & Liberal & $\begin{array}{l}\text { Etelvina dos Santos de } \\
\text { Oliveira Lima, em 1874 }\end{array}$ \\
\hline $\begin{array}{l}\text { 7. Dr. José Joaquim Franco do } \\
\text { Valle }\end{array}$ & 784 & 27 & Médico & Liberal & $\begin{array}{l}\text { Anardina Lecticia de } \\
\text { Jesus Brandão, em 1865 }\end{array}$ \\
\hline $\begin{array}{l}\text { 8. Tibúrcio Borges de Macedo, } \\
\text { Capitão }\end{array}$ & 781 & Reeleito - Liberal & \multicolumn{3}{|l|}{} \\
\hline $\begin{array}{l}\text { 9. Caetano José Munhoz, Tenente } \\
\text { Coronel }\end{array}$ & 780 & 52 & $\begin{array}{l}\text { Industrial } \\
\text { erva-mate }\end{array}$ & Conservador & $\begin{array}{l}\text { Francisca de Assis de } \\
\text { Oliveira, em 1840 }\end{array}$ \\
\hline $\begin{array}{l}\text { Suplentes: Dr. Tertuliano Teixeira de Freitas, 780, Conservador; Dr. Bento Fernandes de Barros, 779, } \\
\text { Conservador; Antonio Augusto Ferreira de Moura, Capitão, 775, Liberal; Candido Martins Lopes, 774, Liberal; } \\
\text { Francisco Pereira Alves, Capitão, 772; Francisco Ignacio da Rocha, 768, Conservador; Antonio Enes Bandeira, } \\
\text { Capitão, 767, Liberal; Antonio Jacintho Nóbrega, Tenente, 764; Fracisco Antonio Nóbrega, Capitão, 763; }\end{array}$ \\
\hline
\end{tabular}

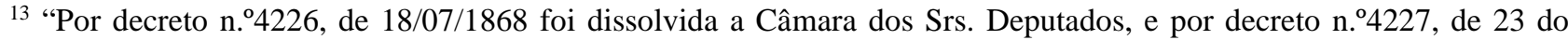
mesmo mês e ano foi convocada outra, para cuja eleição foi marcada o dia 31/01/1869, devendo neste dia proceder-se em todo o Império a eleição dos respectivos eleitores" (PARANÁ, 1869, p.2). 


\begin{tabular}{|c|c|c|c|c|c|}
\hline \multicolumn{6}{|c|}{ Seguem-se mais 40 nomes de cidadãos menos votados. } \\
\hline JUÍZES DE PAZ - Curitiba & Votos & Idade & Profissão & Partido & Esposa / Ano casamento \\
\hline 1. Dr. João José Pedrosa & 474 & 24 & Advogado & Liberal & Solteiro \\
\hline $\begin{array}{l}\text { 2. Tiburcio Borges de Macedo, } \\
\text { Capitão }\end{array}$ & 467 & \multicolumn{4}{|c|}{ Eleito também vereador - Liberal } \\
\hline $\begin{array}{lll}\text { 3. Dr. Generoso Marques dos } \\
\text { Santos }\end{array}$ & 466 & \multicolumn{4}{|c|}{ Eleito também vereador - Liberal } \\
\hline 4. Bento Florêncio Munhoz, Major & 466 & \multicolumn{4}{|c|}{ Reeleito - Conservador } \\
\hline
\end{tabular}

Fonte: Dezenove de Dezembro, 07/10/1868 (para os resultados eleitorais de vereadores); Dezenove de Dezembro, 12/09/1868 (para os resultados eleitorais de juízes de paz); Lista de Votantes qualificados de Curitiba, 1855 e 1861 (idade e profissão); NEGRÃO, 1926, 1927, 1928, 1929, 1946, 1950 (para as demais informações).

A Câmara de Curitiba ficou composta por quatro advogados, sendo três deles recém formados na mesma turma. E destaca-se tradicional família paranaense Munhoz ${ }^{14}$.

Esta foi uma eleição bastante confusa e conturbada, como visto, principalmente devido a mudança de Gabinete no Rio de Janeiro. E, posteriormente, esta eleição foi "declarada nula" pelo Presidente da Província, mas dependia ainda "de decisão do governo imperial" (PARANÁ, 1869, p.2) para se marcar nova eleição, e que aconteceu apenas em 20/03/1870, mas que foi novamente anulada pelo Presidente da Província (PARANÁ, 1871, p.1). O Dr. Agostinho Ermelino de Leão, Vice-presidente da Província, autorizou nova eleição para o dia 27/11/1870, mas que foi adiada. Dentro desta indefinição, certamente esta foi uma gestão municipal bastante difícil. E, por fim, em 09/07/1871, outra eleição foi realizada, como demonstra a Tabela 5, sendo eleita uma nova Câmara de vereadores, agora toda Conservadora, tomando posse em 01/08/1871, para o curto período de mandato de um ano e cinco meses. Outro fator da dinâmica das eleições no Império, era a de que os votantes do partido opositor acabavam sendo excluídos das listas de votação para que os candidatos "oficiais" pudessem sair vitoriosos com maior facilidade.

Eis o resultado da eleição municipal extraordinária de 09/07/1871:

\footnotetext{
${ }^{14}$ A tradicional família Munhoz também tem ligações com Baltazar Carrasco dos Reis, por parte de Luiza Licia de Lima, casada com Florêncio José Munhoz, Tenente, natural de Paranaguá, proprietário de um campo de criação de gado no Itinga (OLIVEIRA, 2001). Florêncio e Luiza são os pais de Caetano e Bento, que por sua vez, tiveram casamentos estratégicos, Caetano com Francisca de Assis de Oliveira, irmã de Manoel de Oliveira Franco e Bento com Maria do Céo Taborda Ribas, filha do capitão Ricardo Jose Taborda Ribas e Francisca Joaquina de Andrade, de famílias tradicionais. Muitos políticos foram descendentes dos Munhoz, entre eles Bento Munhoz da Rocha Neto, governador do Paraná entre 1951 a 1955, chegando a Ministro da Agricultura, em 1955 (OLIVEIRA, 2001).
} 
Tabela 5 - Vereadores e Juízes de paz em Curitiba, 1871-1872

\begin{tabular}{|c|c|c|c|c|c|}
\hline VEREADORES - Curitiba & Votos & Idade & Profissão & Partido & Esposa / Ano casamento \\
\hline $\begin{array}{l}\text { 1. Dr. Tertuliano Teixeira de Freitas } \\
\text { (Presidente) }\end{array}$ & 583 & 36 & Advogado & $\begin{array}{l}\text { Conservador, } \\
\text { chefe }\end{array}$ & $\begin{array}{l}\text { Helena Augusta Teixeira } \\
\text { de Lima, sua sobrinha, } \\
\text { em } 1860 \text {, no RJ }\end{array}$ \\
\hline $\begin{array}{lll}\text { 2. Paulino de } & \text { Oliveira Franco, } \\
\text { Tenente Coronel } & & \\
\end{array}$ & 580 & 41 & Negociante & Conservador & $\begin{array}{l}\text { Mathilde Januária de } \\
\text { Souza, sua sobrinha }\end{array}$ \\
\hline 3. Francisco Ignácio da Rocha & 562 & $?$ & Negociante & Conservador & Maria da Conceição \\
\hline 4. João Baptista de Oliveira & 546 & $?$ & Fazendeiro & Conservador & $?$ \\
\hline 5. João Bittencourt, Capitão & 526 & 35 & $\begin{array}{l}\text { Negociante, } \\
\text { Funcionário } \\
\text { público }\end{array}$ & Conservador & Balbina Negrão \\
\hline 6. João Fabiano Cabral, Tenente & 519 & 43 & Fazendeiro & Conservador & Anna Maria da Fontoura \\
\hline $\begin{array}{l}\text { 7. Antonio Francisco Correia de } \\
\text { Bittencourt, Alferes }\end{array}$ & 506 & 33 & Negociante & Conservador & $\begin{array}{l}\text { Maria Francisca da Cruz } \\
\text { Biscaia, em } 1866\end{array}$ \\
\hline 8. José de Camargo Pinto, Tenente & 500 & $?$ & Fazendeiro & Conservador & $\begin{array}{l}\text { Leodobina Francisca da } \\
\text { Costa }\end{array}$ \\
\hline 9. Tristão da Silva Pereira, Alferes & 490 & 37 & Negociante & Conservador & $\begin{array}{l}\text { Izabel Pereira; } 2^{\mathrm{a}} \text { núpcias } \\
\text { com Benedicta do Carmo } \\
\text { Britto. }\end{array}$ \\
\hline Seguem os suplentes & - & & & & \\
\hline Juízes de paz - Curitiba & Votos & Idade & Profissão & Partido & Esposa / Ano casamento \\
\hline $\begin{array}{l}\text { 1. Manoel de Oliveira Franco, } \\
\text { Brigadeiro }\end{array}$ & 604 & 57 & $\begin{array}{l}\text { Funcionário } \\
\text { público }\end{array}$ & $\begin{array}{l}\text { Conservador, } \\
\text { chefe }\end{array}$ & $\begin{array}{l}\text { Escolástica Joaquina de } \\
\text { Sá Ribas, em } 1838\end{array}$ \\
\hline $\begin{array}{l}\text { 2. José Correia de Bittencourt, } \\
\text { Tenente Coronel }\end{array}$ & 590 & 41 & Negociante & $\begin{array}{l}\text { Conservador, } \\
\text { chefe }\end{array}$ & Escolástica Ribas Franco \\
\hline $\begin{array}{l}\text { 3. Aurélio Ribeiro de Campos, } \\
\text { Capitão }\end{array}$ & 545 & 29 & $\begin{array}{l}\text { Funcionário } \\
\text { público, } \\
\text { Militar }\end{array}$ & Conservador & $\begin{array}{lll}\text { Alexandrina } & \text { Maria dos } \\
\text { Santos } & & \end{array}$ \\
\hline 4. Norberto Nunes Barbosa, Capitão & 520 & 66 & $\begin{array}{l}\text { Negociante, } \\
\text { Fazendeiro }\end{array}$ & Conservador & $\begin{array}{l}\text { Rita de Oliveira Ribas, } \\
\text { em } 1831\end{array}$ \\
\hline Seguem os suplentes & - & & & & \\
\hline
\end{tabular}

Fonte: Dezenove de Dezembro, 15/07/1871 (para o resultado eleitoral); Lista de Votantes qualificados de Curitiba, 1855 e 1861 (idade e profissão); NEGRÃO, 1926, 1927, 1928, 1929, 1946, 1950 (para as demais informações).

Há uma renovação total da Câmara de vereadores e de juízes de paz, com a presença apenas de políticos Conservadores. Esta breve legislatura está toda vinculada a Manoel de Oliveira Franco [Brigadeiro Franco] e à família Bittencourt ${ }^{15}$.

Porém, na próxima eleição municipal marcada para o dia 07/09/1872, apareceu um forte desentendimento dentro do próprio Partido Conservador de Curitiba, principalmente entre suas duas grandes lideranças, o Brigadeiro Franco e o Dr. Tertuliano Teixeira de Freitas. E o grupo do Dr. Tertuliano Teixeira de Freitas saiu vitorioso. A surpresa foi a presença de líderes Liberais em meio aos Conservadores, como o jovem Dr. João José Pedrosa, o Capitão Antonio Augusto Ferreira de Moura, entre outros, demonstrando uma aliança entre os "clãs eleitorais".

\footnotetext{
${ }^{15}$ Quanto aos Bittencourt, também de avós portugueses (José Corrêa Bittencourt e Rosa Mariana), seus dois filhos contraíram matrimônio com mulheres das famílias tradicionais e, igualmente, seus netos e netas (NEGRÃO, 1929). Muitos políticos no século XX são descendentes destas duas famílias, Bittencourt e Oliveira Franco (OLIVEIRA, 2001).
} 
Tabela 6 - Vereadores e Juízes de Paz de Curitiba, 1873-1876

\begin{tabular}{|c|c|c|c|c|c|}
\hline VEREADORES & Votos & Idade & Profissão & Partido & Esposa / Ano casamento \\
\hline $\begin{array}{l}\text { 1. Dr. João José } \text { Pedrosa } \\
\text { (Presidente) }\end{array}$ & 381 & 27 & Advogado & Liberal & Solteiro \\
\hline 2. Dr. Tertuliano Teixeira de Freitas & 380 & \multicolumn{4}{|c|}{ Reeleito - Conservador } \\
\hline $\begin{array}{l}\text { 3. Lourenço Taborda Ribas de } \\
\text { Andrade, Tenente }\end{array}$ & 360 & 38 & Negociante & Conservador & Maria José dos Santos \\
\hline $\begin{array}{l}\text { 4. Antonio Augusto Ferreira de } \\
\text { Moura, Capitão }\end{array}$ & 358 & \multicolumn{4}{|c|}{ Reeleito - Liberal } \\
\hline 5. Tristão da Silva Pereira, Tenente & 357 & \multicolumn{4}{|c|}{ Reeleito - Conservador } \\
\hline 6. Antonio Marçal de Oliveira & 356 & $?$ & Negociante & Liberal & $\begin{array}{ll}\text { Hermancia } & \text { Borges } \\
\text { Guimarães } & \end{array}$ \\
\hline 7. Vicente Ferreira da Luz, Major & 356 & 61 & $\begin{array}{l}\text { Industrial } \\
\text { erva-mate }\end{array}$ & Conservador & $\begin{array}{l}\text { Florencia do Amaral, em } \\
1844\end{array}$ \\
\hline $\begin{array}{l}\text { 8. Joaquim Ventura de Almeida } \\
\text { Torres, Tenente }\end{array}$ & 351 & 42 & $\begin{array}{l}\text { Industrial } \\
\text { erva-mate }\end{array}$ & Liberal & $\begin{array}{l}\text { Maria da Luz Osório } \\
\text { Borges }\end{array}$ \\
\hline 9. Antonio Enes Bandeira, Capitão & 350 & 44 & Negociante & Liberal & $\begin{array}{l}\text { Felicidade } \quad \text { Ferreira } \\
\text { Borges }\end{array}$ \\
\hline Seguem suplentes & \multicolumn{5}{|l|}{ - } \\
\hline Juízes de paz & Votos & Idade & Profissão & Partido & Esposa / Ano casamento \\
\hline $\begin{array}{l}\text { 1. José Manoel Marques da Silva, } \\
\text { Tenente }\end{array}$ & 352 & $?$ & $\begin{array}{l}\text { Funcionário } \\
\text { público }\end{array}$ & Conservador & $\begin{array}{l}\text { Francisca Lourenço dos } \\
\text { Santos, em } 1861 \text { ou } 1871\end{array}$ \\
\hline $\begin{array}{l}\text { 2. Lourenço Taborda Ribas de } \\
\text { Andrade, Tenente }\end{array}$ & 351 & \multicolumn{4}{|c|}{ Eleito também Vereador - Conservador } \\
\hline 3. Ricardo Affonso Coelho, Capitão & 348 & 41 & $\begin{array}{l}\text { Negociante, } \\
\text { Funcionário } \\
\text { público }\end{array}$ & Liberal & $\begin{array}{lll}\text { Virginia } & \text { Marques dos } \\
\text { Santos } & \end{array}$ \\
\hline $\begin{array}{l}\text { 4. Manoel Gonçalves dos Santos, } \\
\text { Capitão }\end{array}$ & 337 & \multicolumn{4}{|c|}{ Reeleito - Liberal } \\
\hline
\end{tabular}

Fonte: Dezenove de Dezembro, 11/09/1872 e 14/09/1872 (para o resultado eleitoral); Lista de Votantes qualificados de Curitiba, 1855 e 1861 (idade e profissão); NEGRÃO, 1926, 1927, 1928, 1929, 1946, 1950 (para as demais informações).

Desta legislatura destaca-se os conservadores divididos. Quanto às famílias tradicionais, tem-se a família Ribas ${ }^{16}$. A próxima eleição municipal ocorreu no dia 01/10/1876.

Tabela 7 - Vereadores e Juízes de Paz de Curitiba, 1877-1880

\begin{tabular}{|l|l|l|l|l|l|l|}
\hline VEREADORES - Curitiba & Votos & Idade & Profissão & Partido & Esposa / Ano casamento \\
\hline $\begin{array}{l}\text { 1. Dr. Tertuliano Teixeira de } \\
\text { Freitas (Presidente) }\end{array}$ & - & \multicolumn{5}{|l|}{ Reeleito - Conservador } \\
\hline $\begin{array}{l}\text { 2. Lourenço Taborda Ribas de } \\
\text { Andrade }\end{array}$ & - & \multicolumn{5}{|l|}{ Reeleito - Conservador } \\
\hline $\begin{array}{l}\text { 3. Antonio Ricardo de Souza Dias } \\
\text { Negrão }\end{array}$ & - & 31 & $\begin{array}{l}\text { Funcionário } \\
\text { público }\end{array}$ & Conservador & $\begin{array}{l}\text { Nercinda da } \\
\text { Ribeiro }\end{array}$ & Motta \\
\hline 4. Aurélio Ribeiro de Campos & - & \multicolumn{3}{|l|}{ Reeleito - Conservador } \\
\hline $\begin{array}{l}\text { 5. Joaquim Ventura de Almeida } \\
\text { Torres }\end{array}$ & - & \multicolumn{3}{|l|}{ Reeleito - Liberal } \\
\hline 6. José Lourenço de Vasconcellos & - & 34 & Militar & Conservador & Francisca de Sá Ribas, \\
\hline
\end{tabular}

\footnotetext{
${ }^{16}$ A família Ribas também é descendente de Baltazar Carrasco dos Reis e de João Rodrigues Seixas, ambos primeiros povoadores de Curitiba, desde o século XVII, e com muitos de seus membros ocupando os cargos eletivos, inclusive avançando no tempo da República (OLIVEIRA, 2001).
} 


\begin{tabular}{|c|c|c|c|c|c|}
\hline Chaves & & & & & em 1871 \\
\hline 7. Caetano José Munhoz & - & \multicolumn{4}{|c|}{ Reeleito - Conservador } \\
\hline $\begin{array}{l}\text { 8. Florindo da Motta Bandeira e } \\
\text { Silva, Alferes (Presidente/1880) }\end{array}$ & - & 26 & Negociante & Liberal & Solteiro \\
\hline 9. João dos Santos Biscaia & - & 35 & Industrial & Liberal & $\begin{array}{l}\text { Maria José Ribeiro, em } \\
1866\end{array}$ \\
\hline \multicolumn{6}{|c|}{$\begin{array}{l}\text { Seguem os suplentes que assumiram o cargo de vereador ao longo deste quatriênio: Isaías Augusto Alves, } \\
\text { Conservador; Antonio Marçal de Oliveira, Liberal; Antonio Ennes Bandeira, Liberal; Antonio Augusto Ferreira } \\
\text { de Moura, Liberal; Tristão da Silva Pereira, Conservador; Manoel José Felix, Conservador. }\end{array}$} \\
\hline Juízes de paz - Curitiba & Votos & Idade & Profissão & Partido & Esposa / Ano casamento \\
\hline $\begin{array}{l}\text { 1. José Manoel Marques da Silva, } \\
\text { Capitão }\end{array}$ & - & \multicolumn{4}{|c|}{ Reeleito - Conservador } \\
\hline $\begin{array}{l}\text { 2. José Antonio de Lima Castro, } \\
\text { Capitão }\end{array}$ & - & 64 & Negociante & Conservador & $\begin{array}{lll}\text { Anna } & \text { Joaquina } & \text { dos } \\
\text { Santos } & & \\
\end{array}$ \\
\hline 3. Antonio Ferreira da Costa & - & $?$ & Professor & Conservador & $\begin{array}{ll}\text { Francisca } & \text { Ribeiro da } \\
\text { Costa } & \end{array}$ \\
\hline $\begin{array}{l}\text { 4. Joaquim José Belarmino de } \\
\text { Bittencourt, Capitão }\end{array}$ & - & 38 & Negociante & Conservador & $\begin{array}{l}\text { Libânia } \text { Carneiro, em } \\
1867\end{array}$ \\
\hline Seguem os suplentes & \multicolumn{5}{|l|}{ - } \\
\hline
\end{tabular}

Fonte: Almanak da Província do Paraná, 1876 a 1880 (para os nomes dos vereadores e juízes de paz, sem a publicação do resultado do número de votos); NEGRÃO, 1926, 1927, 1928, 1929, 1946, 1950 (para as demais informações).

Novamente foi uma eleição em que vereadores dos dois partidos foram eleitos. Destaca-se, nesta dinâmica eleitoral local, a família Almeida Torres ${ }^{17}$.

Porém, nesta legislatura aconteceu a famigerada mudança de Gabinete no Império, voltando os Liberais ao poder, em 05/01/1878. Isto causou inúmeros problemas para esta administração municipal, a partir de 1878 .

Neste clima de início de década, a próxima eleição municipal em Curitiba aconteceu no dia 05/07/1880, sendo que os Liberais estavam no poder no Rio de Janeiro.

Tabela 8 - Vereadores e Juízes de Paz de Curitiba, 1881/1882

\begin{tabular}{|l|l|l|l|l|l|l|}
\hline VEREADORES - Curitiba & Votos & Idade & Profissão & Partido & Esposa / Ano Casamento \\
\hline $\begin{array}{l}\text { 1. Dr. Generoso Marques dos } \\
\text { Santos (Presidente) }\end{array}$ & 610 & \multicolumn{3}{|l|}{ Reeleito - Liberal (Chefe) } \\
\hline 2. João Baptista Ribeiro, Capitão & 531 & 43 & Negociante & Liberal & Maria Joanna Gonçalves \\
\hline $\begin{array}{l}\text { 3. Dr. Francisco de Almeida } \\
\text { Torres }\end{array}$ & 511 & 33 & Engenheiro & Liberal & $\begin{array}{l}\text { Adelaide } \\
\text { Nascimento, em } 1877\end{array}$ \\
\hline 4. Sizenando de Sá Ribas, Capitão & 507 & \multicolumn{2}{|l|}{ Reeleito - Liberal } \\
\hline 5. João Tobias Pinto Rebello & 478 & 37 & Negociante & Liberal & Virgília de Macedo \\
\hline $\begin{array}{l}\text { 6. Antonio Augusto Ferreira de } \\
\text { Moura }\end{array}$ & 474 & \multicolumn{2}{|l|}{ Reeleito - Liberal } \\
\hline 7. João Lustosa de Andrade & 464 & 34 & Negociante & Liberal & Anna Flora Rodrigo \\
\hline 8. Pedro Luiz de Souza Rocha & 460 & 30 & Negociante & Liberal & Maria Rita de Oliveira \\
\hline 9. João dos Santos Biscaia & 424 & Reeleito - Liberal \\
\hline Seguem suplentes & - & \multicolumn{7}{|l|}{} \\
\hline Juízes de paz - Curitiba & Votos Idade & Profissão & Partido & Esposa / Ano casamento \\
\hline
\end{tabular}

${ }^{17}$ Quanto à família Almeida Torres em Curitiba, descende do $2^{\text {o }}$ Visconde de Macaé, José Carlos Pereira de Almeida Torres, que teria tido um filho com uma escrava, o senhor Mariano de Almeida Torres, quando exerceu a magistratura nesta região de Curitiba. Mariano de Almeida Torres casou com Anna Maria do Espírito Santo e tiveram inúmeros filhos, todos influentes no desenvolvimento econômico paranaense no século XIX e também participantes ativos na política local. Os filhos casaram com outras famílias tradicionais da região (ALVES, 2015). 


\begin{tabular}{|l|l|l|l|l|l|}
\hline $\begin{array}{l}\text { 1. Joaquim Ventura de Almeida } \\
\text { Torres }\end{array}$ & 718 & \multicolumn{3}{|l|}{ Reeleito - Liberal } \\
\hline $\begin{array}{l}\text { 2. Francisco de Paula Ribeiro } \\
\text { Vianna }\end{array}$ & 710 & $?$ & $\begin{array}{l}\text { Funcionário } \\
\text { público }\end{array}$ & Liberal & Francisca Munhoz \\
\hline 3. João de Macedo Rangel & 703 & $?$ & $\begin{array}{l}\text { Tabelião de } \\
\text { notas }\end{array}$ & Liberal & $\begin{array}{l}\text { Maria da Luz Ozório, em } \\
1872 ; 2^{a} \text { núpcias com Maria } \\
\text { da Glória Craveiro, em 1884 }\end{array}$ \\
\hline 4. Ignácio de Paula França & 603 & $?$ & $\begin{array}{l}\text { Negociante, } \\
\text { Funcionário } \\
\text { público }\end{array}$ & Liberal & $\begin{array}{l}\text { Amélia Pereira Jorge; 2 } \\
\text { núpcias com Izabel Cortes }\end{array}$ \\
\hline Seguem suplentes & & & \\
\hline
\end{tabular}

Fonte: Dezenove de Dezembro, 10/07/1880; NEGRÃO, 1926, 1927, 1928, 1929, 1946, 1950 (para as demais informações).

Destaca-se, nesta legislatura, a família Pinto Rebello ${ }^{18}$.

Após esta eleição, aconteceu uma ampla reforma no sistema eleitoral brasileiro, a chamada Lei Saraiva (Lei $n^{\circ} 3.029$, de 09/01/1881 e regulamentada pelo Decreto $n^{\circ}$ 8.213, de 13/08/1881), que exigiu recadastramento dos eleitores, eliminando os chamados votantes, continuando a renda ser a forma de acesso ao processo eleitoral e excluindo os analfabetos. Neste sentido, como se verá adiante, o número de eleitores diminuiu drasticamente e apenas gradativamente voltou a incorporar um maior número de cidadãos.

E, a nova lei exigiu também uma nova eleição para vereadores que foi realizada no dia 01/07/1882, no qual compareceram 251 eleitores (Gazeta Paranaense, Curitiba, 01/07/1882). Eis o resultado:

Tabela 9 - Vereadores e Juízes de Paz de Curitiba, 1883-1886

\begin{tabular}{|l|l|l|l|l|l|}
\hline VEREADORES - Curitiba & Votos & Idade & Profissão & Partido & Esposa / Ano casamento \\
\hline $\begin{array}{l}\text { 1. Dr. Trajano Joaquim dos } \\
\text { Reis (Presidente 1883/84) }\end{array}$ & 27 & 31 & Médico & Liberal & $\begin{array}{l}\text { Josephina Drumond dos } \\
\text { Reis }\end{array}$ \\
\hline 2. Fidelis Augusto de Andrade & 25 & 32 & Negociante & Liberal & Ubaldina de Macedo \\
\hline 3. Augusto Stelfeld & 25 & 66 & Farmacêutico & Liberal & $\begin{array}{l}\text { Carlota Sophia Dorothéa } \\
\text { Kalckmann, em 1852 }\end{array}$ \\
\hline $\begin{array}{l}\text { 4. Nicolau Pinto Rebello } \\
\text { 5. Joaquim José Belarmino de } \\
\text { Bittencourt }\end{array}$ & 25 & 48 & $\begin{array}{l}\text { Negociante, } \\
\text { Industrial }\end{array}$ & Liberal & $\begin{array}{l}\text { Herminia } \\
\text { Marques }\end{array}$ \\
\hline $\begin{array}{l}\text { 6. José Inocêncio de França } \\
\text { Joaquim Ventura de }\end{array}$ & 24 & $?$ & $\begin{array}{l}\text { Industrial } \\
\text { erva-mate }\end{array}$ & Liberal & $\begin{array}{l}\text { Maria } \\
\text { Nóbrega }\end{array}$ \\
\hline $\begin{array}{l}\text { 7lmeida Torres } \\
\text { Alemência }\end{array}$ \\
\hline
\end{tabular}

${ }^{18}$ Os Pinto Rebello são descendentes pelo lado paterno do português Nicolau Pinto Rebello, o velho, e de seu filho Tobias Pinto Rebello, que era vereador em Curitiba entre 1852/55 e casado com Benedicta Francisca de Assis Andrade, da família do Sargento Mór Ignácio Lustosa de Andrade, que os faz parentes de inúmeras outras famílias. Tobias e Benedicta são pais dos vereadores João Tobias, Nicolau e José Pinto Rebello. "Membros da família Pinto Rebello casaram-se com várias famílias igualmente importantes como os Macedo, Taborda Ribas e outros" (OLIVEIRA, 2001, p.288). 


\begin{tabular}{|c|c|c|c|c|c|}
\hline 8. Mathias Taborda Ribas* & 22 e 39 & 50 & $\begin{array}{l}\text { Industrial } \\
\text { erva-mate }\end{array}$ & Conservador & Balbina Licia Munhoz \\
\hline 9. Isaías Augusto Alves* & 20 e 39 & $?$ & $\begin{array}{l}\text { Cartorário; } \\
\text { Funcionário } \\
\text { público }\end{array}$ & Conservador & $\begin{array}{l}\text { Thomazia Carolina } \\
\text { Pedrosa, em } 1874\end{array}$ \\
\hline \multicolumn{6}{|c|}{ Seguem suplentes que assumiram o cargo de vereador: } \\
\hline $\begin{array}{l}\text { Antonio Francisco Correia de } \\
\text { Bittencourt }\end{array}$ & 20 & \multicolumn{4}{|c|}{ Reeleito - Conservador } \\
\hline $\begin{array}{l}\text { Manoel Gonçalves dos Santos } \\
\text { (Presidente, 1884/85) }\end{array}$ & 13 & \multicolumn{4}{|c|}{ Reeleito - Liberal } \\
\hline $\begin{array}{lll}\text { João } & \text { Lourenço } & \text { Taborda } \\
\text { Ribas* } & & \\
\end{array}$ & 58 & 29 & Negociante & Liberal & $\begin{array}{l}\text { Maria Catharina Taborda } \\
\text { Ribas, em } 1884\end{array}$ \\
\hline $\begin{array}{l}\text { Emydgio Westphalen - } \\
\text { assume em nova eleição }\end{array}$ & 201 & 36 & Advogado & Liberal & $\begin{array}{l}\text { Joaquina de Paula Xavier; } \\
2^{\mathrm{a}} \text { núpcias com Januária } \\
\text { B. Carvalho de Oliveira, } \\
\text { em } 1877\end{array}$ \\
\hline Juízes de paz - Curitiba & Votos & Idade & Profissão & Partido & Esposa / Ano casamento \\
\hline 1. Pedro Luiz de Souza Rocha & 133 & \multicolumn{4}{|c|}{ Reeleito - Liberal } \\
\hline 2. João Tobias Pinto Rebello & 132 & \multicolumn{4}{|c|}{ Reeleito - Liberal } \\
\hline 3. Theophilo Moreira Garcez & 133 & $?$ & Negociante & Liberal & Philomenia Vianna \\
\hline 4. João Lustosa de Andrade & 131 & \multicolumn{4}{|c|}{ Reeleito - Liberal } \\
\hline \multicolumn{6}{|c|}{$\begin{array}{l}\text { Seguem os menos votados, como: Manoel José da Cunha Bittencourt, 112; João Carvalho de Oliveira Junior, } \\
\text { 113; Eduardo Augusto de Vasconcellos Chaves, 111; Guilherme Xavier de Miranda, 110; entre outros. }\end{array}$} \\
\hline
\end{tabular}

Ficou visível o ínfimo número de eleitores que elegeu esta nova Câmara municipal.

O jovem médico Dr. Trajano Joaquim dos Reis era natural da Bahia e chega a Curitiba junto com sua esposa em 1876. O farmacêutico alemão Augusto Stellfeld possuía farmácia no centro da capital Curitiba, instalada desde 1856, portanto, conhecido de toda a população local. Apesar dos dois novos vereadores não pertencerem às tradicionais famílias curitibanas, os demais seguem a mesma composição das legislaturas anteriores.

A volta dos Conservadores ao poder no Rio de Janeiro se deu em 20/08/1885, com o Barão de Cotegipe, em uma nova mudança de Gabinete. Esta mudança influenciou a composição da próxima Câmara de Curitiba, sendo também a última eleição municipal no Império, no dia 01/07/1886. Agora os Conservadores estavam sob a liderança de um outro grande "clã parental" paranaense, a família Correia e destaque a família Pinto Rebello ${ }^{19}$.

\footnotetext{
${ }^{19} \mathrm{O}$ comendador Ildefonso Pereira Correia, presidente da Câmara, negociante e industrial da erva-mate, era irmão do Senador pelo Paraná, Dr. Manoel Francisco Correia. O pai deles foi deputado provincial na $1^{\text {a }}$ legislatura do Paraná em 1854/55, além de árduo batalhador pela emancipação política desta região. Ildefonso Pereira Correia recebeu o título de Barão do Serro Azul em 08/08/1888. Da família Pinto Rebello, José Pinto Rebello, negociante e industrial da ervamate, casou com Francisca da Luz dos Santos, filha do importante industrial da erva-mate em Antonina e Morretes, Coronel José Antonio dos Santos. A filha Etelvina Pinto Rebello casou com o Dr. Affonso Alves de Camargo, que chegou a ser Governador do Paraná em 1916/20 e 1928/30, além de outros cargos públicos e eletivos. Affonso Alves de Camargo foi um dos mais importantes políticos da $1^{\mathrm{a}}$ República no Paraná. Outro vereador foi Fausto Bento Vianna, 
Tabela 10 - Vereadores e Juízes de Paz de Curitiba, 1887-1889

\begin{tabular}{|c|c|c|c|c|c|}
\hline VEREADORES - Curitiba & Votos & Idade & Profissão & Partido & Esposa / Ano casamento \\
\hline $\begin{array}{l}\text { 1. Comendador Ildefonso } \\
\text { Pereira Correia (Presidente) }\end{array}$ & 49 & 42 & $\begin{array}{l}\text { Negociante, } \\
\text { Industrial } \\
\text { erva-mate }\end{array}$ & Conservador & $\begin{array}{l}\text { Maria José Correia, em } \\
1871\end{array}$ \\
\hline $\begin{array}{l}\text { 2. Antonio Ricardo do } \\
\text { Nascimento }\end{array}$ & 43 & $?$ & $\begin{array}{l}\text { Negociante, } \\
\text { Industrial } \\
\text { erva-mate }\end{array}$ & Liberal & 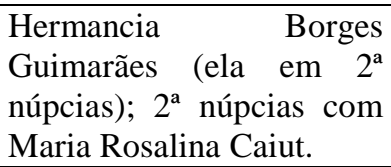 \\
\hline 3. José Theodoro de Freitas & 42 & 53 & $\begin{array}{l}\text { Funcionário } \\
\text { público }\end{array}$ & Conservador & Maria de Freitas \\
\hline 4. José Pinto Rebello & 42 & 47 & $\begin{array}{l}\text { Negociante, } \\
\text { Industrial } \\
\text { erva-mate }\end{array}$ & Liberal & $\begin{array}{l}\text { Francisca da Luz dos } \\
\text { Santos, em } 1870\end{array}$ \\
\hline $\begin{array}{l}\text { 5. Dr. Francisco de Camargo } \\
\text { Pinto (Vice-presidente) }\end{array}$ & 41 & 44 & $\begin{array}{l}\text { Engenheiro } \\
\text { civil }\end{array}$ & Conservador & $?$ \\
\hline 6. Tobias de Macedo & 41 & $?$ & Negociante & Liberal & Rosa Fonseca \\
\hline 7. Eugenio Bendazeski & 40 & $?$ & Negociante & Conservador & Olga Bendazeski \\
\hline $\begin{array}{l}\text { 8. Guilherme Xavier de } \\
\text { Miranda }\end{array}$ & 39 & 43 & $\begin{array}{l}\text { Negociante, } \\
\text { Industrial } \\
\text { erva-mate }\end{array}$ & Conservador & $\begin{array}{l}\text { Anália Agner; } 2^{\mathrm{a}} \text { núpcias } \\
\text { com Maria Rosa de } \\
\text { Bittencourt }\end{array}$ \\
\hline
\end{tabular}

Seguem os menos votados que disputaram uma vaga no $2^{\circ}$ escrutínio, no dia 04/08/1886: Antonio Augusto Ferreira de Moura*, 28; Dr. Francisco de Camargo Pinto*, 24; Dr. Eduardo Mendes Gonçalves, 15; João dos Santos Biscaia, 14; João Desiderio Baebler*, 4; José Carvalho de Oliveira*, 3; Luiz Antonio Requião, 2; Gregório Affonso Garcez, 2. E o eleito foi:

9. Antonio Augusto Ferreira $70 \quad$ Reeleito - Liberal de Moura, Capitão

\begin{tabular}{|c|c|c|c|c|c|}
\hline Juízes de paz - Curitiba & Votos & Idade & Profissão & Partido & Esposa / Ano casamento \\
\hline
\end{tabular}

1. Antonio Francisco 231 Reeleito - Conservador

Correia de Bittencourt

2. Joaquim José Bellarmino 225 Reeleito - Conservador de Bittencourt

\begin{tabular}{|l|l|l|l|l|l|l|}
\hline 3. Fausto Bento Vianna & 218 & $?$ & Negociante & Conservador & $\begin{array}{l}\text { Fortunata de Oliveira } \\
\text { Vianna }\end{array}$ \\
\hline 4. João de Almeida Torres & 209 & $?$ & Negociante & Liberal & $?$ \\
\hline
\end{tabular}

Seguem-se outros menos votados: João Tobias Pinto Rebello, 140; João Lustosa de Andrade, 140; Manoel Gonçalves dos Santos, 140; Fidelis Augusto de Andrade, 139; entre outros

Fonte: Dezenove de Dezembro, 01/07/1886 (Em Curitiba teve duas seções de recepção de votos, a primeira era presidente da mesa Theophilo Moreira Garcez, e da segunda era presidente José Pinto Rebello - foram somados os votos das duas seções com o resultado final acima exposto - Dezenove de Dezembro, 02/07/1886);

* Vereadores que assumiram o cargo ao longo desta Legislatura.

Esta Câmara tomou posse em 07/01/1887.

Nesta Câmara chama a atenção que todos os políticos são das tradicionais famílias curitibanas, exceto Eugênio Bendazeski, alemão, mas sua irmã era casada com a família Lustosa de Andrade. E, em especial coincidência, as figuras do Comendador Ildefonso Pereira Correia $e$ Fausto Bento Viana em que seus pais se destacaram pela luta em prol da emancipação política

filho do capitão Floriano Bento Vianna, natural de Paranaguá, cujo nome ficou gravado na História do Paraná por pedir a emancipação política de Paranaguá e Curitiba em 1821. 
paranaense desde o início do século XIX. E quanto à profissão destes vereadores e juízes de paz, destaca-se o grande número de industriais e negociantes ligados à erva-mate.

Porém, com a Proclamação da República as Câmaras foram dissolvidas e formadas juntas administrativas para gerirem os trabalhos municipais, até a próxima eleição.

\section{CONSIDERAÇÕES FINAIS}

No período de 1856 a 1889, na cidade de Curitiba, capital do Paraná, ocorreram dez eleições municipais válidas, tendo sempre nove vagas para vereadores e quatro para juízes de paz, sendo que 71 políticos ocuparam o cargo de vereador e 24 os de juiz de paz, portanto, alguns sendo reeleitos ao longo deste período e outros sendo substituídos por suplentes.

Foram destacadas as famílias destes políticos, em seus "clãs parentais" e suas relações de parentesco. Ao longo do trabalho foram apresentadas algumas das tradicionais famílias a que estes políticos pertenciam, descendentes de Balthazar Carrasco dos Reis, João Rodrigues de Seixas, João Rodrigues de França, Matheus Martins Leme, que com suas famílias e escravos se estabeleceram ao sul de São Paulo, tanto no litoral quanto na serra, a partir do século XVII. Os Sá Ribas, Lustosa de Andrade, Borges de Macedo, Ferreira de Moura, Marques dos Santos, Munhoz, Oliveira Franco, Bittencourt, Ribas, Almeida Torres, Pinto Rebello, Correia são exemplos de como a genealogia pode auxiliar na compreensão destes grupos atuantes na sociedade paranaense e igualmente a importância do laço matrimonial para ampliar as ligações de parentela ou como forma de ingressar em uma determinada condição de classe. Daí decorre, igualmente, o papel da mulher da elite no século XIX.

Enfim, as eleições em Curitiba podem ser um reflexo de como era o processo democrático no Brasil Império, como um todo, com muitas rixas e desentendimentos, fraudes, forte controle sobre o possível resultado desejado, significativa disputa entre Liberais e Conservadores, representantes dos "clãs parentais" postos em competição com a união em "clãs eleitorais" e o destaque a uma classe dominante, de posse de recursos financeiros (renda) e formação educacional e ligada às famílias tradicionais.

\section{REFERÊNCIAS}

ALVES, Alessandro Cavassin (2015). A província do Paraná e sua Assembleia Legislativa (1853-1889). A força política das famílias tradicionais. Curitiba: Máquina de Escrever. 
(2015).

Disponível

em:

http://www.buratto.org/paulistana/Carrascos.htm. Acesso em 19/11/2015.

LEÃO, Ermelino Agostinho de (1926). Contribuições Históricas e Geographicas para o Diccionário do Paraná. Curityba: Empresa Graphica Paranaense.

NEGRÃO, Francisco (1926, 1927, 1928, 1929, 1946 e 1950). Genealogia Paranaense. Curitiba: Imprensa Paranaense S.A.

OLIVEIRA, Ricardo Costa de (2001). O silêncio dos vencedores. Genealogia, classe dominante e estado do Paraná. Curitiba: Moinho do Verbo.

PEREIRA, Magnus Roberto de (Org.) (1993). Livro dos 300 anos: Câmara Municipal de Curitiba, 1693-1993. Curitiba, Câmara Municipal de Curitiba.

VIANNA, Oliveira (1987). Instituições políticas brasileiras. Belo Horizonte: Itatiaia; São Paulo: Editora da Universidade de São Paulo; Niterói, RJ: Editora da Universidade Federal Fluminense.

Documentos diversos

PARANÁ. (1854). Relatório do Presidente da Província do Paraná. O Conselheiro Zacarias de Góes e Vasconcellos na abertura da Assembleia Legislativa Provincial em 15 de julho de 1854. Curityba, Typ. Paranaense de Cândido Martins Lopes.

PARANÁ. (1869). Relatório com que o Exmo. Sr. Presidente da Província Dr. Antonio Augusto da Fonseca abriu a $2^{\mathrm{a}}$ Sessão da $8^{\mathrm{a}}$ Legislatura da Assembleia Legislativa do Paraná, no dia 6 de abril de 1869. Curityba, Typographia de Cândido Martins Lopes.

PARANÁ. (1871). Relatório apresentado ao Exmo. Sr. Presidente Dr. Venancio José de Oliveira Lisboa pelo Exmo. Sr. Vice-Presidente Dr. Agostinho Ermelino de Leão por ocasião de passar-lhe a Administração da Província do Paraná. Curityba, Typographia de Candido Martins Lopes.

PARANÁ, Lista de votantes qualificados, 1855 e 1861 . Disponível em: http://www.arquivopublico.pr.gov.br/. Acesso em 15/11/2015. Link: Pesquisa por itens documentais (on-line). Digitar: Lista de votantes qualificados.

Jornal consultado: Dezenove de Dezembro. Disponível em http://www.memoria.bn.br. Acesso em $\underline{2015 .}$ 


\title{
ALDERMEN AND PEACE OF JUDGES IN CURITIBA, BETWEEN 1856-1889 \\ FORCE POLICY HOUSEHOLD TRADITIONAL
}

\begin{abstract}
Aldermen and justices of the peace in the Brazilian Empire are part of local political power, with the characteristic of being chosen by regular elections, generally every four years, after 1828 . This work has as its theme therefore present who were these local politicians elected in the city of Curitiba, capital of Paraná, from 1856 to 1889 , a total of 71 councilors and 24 justices of the peace, taking into account the genealogy of these politicians, family, wife, age, profession and political party. The methodology used for this information was reading newspapers of the time, official documents, such as reports of Presidents of Paraná province, lists of qualified voters of the Brazilian laws relating to municipal councils and the elections, in addition to the "Genealogy Paranaense "Francisco Negrao and" silence of the winners, "Ricardo Costa de Oliveira. As a result points to the fundamental importance of "traditional families" or also called "historical families of Paraná" in the process of access to the post of councilor or justice of the peace.
\end{abstract}

Key-words: Local power. Genealogy. Family. Curitiba. Paraná. Brazil century XIX 